\title{
Use of Platelet-Rich Plasma in Autogenous Bone Graft in Implantology
}

\section{Gleycielly da Mota Oliveira Souza', Carolina de Lima Borges², Rosa Natalia Rendall dos Santos Ratis ${ }^{1^{*}}$ and Vivian Kelly Leite Pedrosa ${ }^{1}$}

${ }^{1}$ Dentist Surgeon, Faculdade Integrada de Pernambuco, Brazil

${ }^{2}$ Dentist Surgeon, Resident of Cancer Care and Palliative Care, Instituto de Estudos Avançados da ASCES-UNITA, Brazil

*Corresponding author: Rosa Natalia Rendall dos Santos Ratis, Dentist Surgeon, Faculdade Integrada de Pernambuco, Rua Joana Eliza da Silveira, N²06, Centro, CEP: 54735-290, São Lourenço da Mata-PE, Brazil, Tel: 81-995766880

\begin{abstract}
The use of platelet-rich plasma (PRP) in implantology has potentiated bone regeneration and the healing process, reducing postoperative period, inflammatory process and blood loss. The objective of this study is to verify, based on the literature, the use of PRP in bone regeneration in autogenous grafts, to show its indications and benefits in bone formation and techniques used. A literature review was performed on the efficacy of PRP in autogenous bone grafts in implantology. The databases used were PubMed, Scielo and BVS. In this study, 30 articles from the years 1983 to 2017 were selected demonstrating the effectiveness of the technique. The use of PRP in the dental clinic presents promising results in the regeneration and healing of the tissues, however, more study is needed to verify its long-term efficacy.
\end{abstract}

\section{Keywords}

Bone graft, Maxillary sinus, Platelet-rich plasma, Growth factors

\section{Introduction}

Plasma Rich in Platelets (PRP) is a blood component with a high concentration of autologous platelets in minimal volume of plasma. The platelets present several cell growth factors, constituted by groups of polypeptides acting as regulators and stimulators of the cellular processes of mitogenesis, chemotaxis, differentiation and metabolism [1,2]. The PRP is performed by autologous blood centrifugation, used to improve the integration of bone, cutaneous, cartilaginous or fragile grafts to stimulate wound healing [3-5].
In recent years there has been a growing interest in the use of platelet-rich plasma because it is a simple and inexpensive procedure and a natural way to accelerate and improve wound healing mechanisms. Several protocols were created with the aim of achieving an optimal platelet count and with a higher growth factor [6]. Therefore, studies on this subject are necessary, this review aims to explain the use of PRP in bone regeneration in autogenous grafts, evidence its indications and benefits in bone formation and techniques used, in order to obtain success of this option therapy.

\section{Literature Review}

The evolution of genetic engineering has promoted improvement in the development of materials that have the capacity to induce bone growth factors or osteoinduction, acting directly on bone osteoblastic activity [7].

Among the materials we can mention the platelet rich plasma (PRP), used since the mid-1990s. It was originally found by Lynch, adopting such appointments as platelet gel, platelet-enriched plasma, platelet-rich autogenous plasma, and plasma rich in growth factors. This gel has been extensively studied in dentistry, being used mainly in small bone grafts in the alveolar region for future dental implants and in periodontal and maxillofacial surgeries, aiming to accelerate the repair of the surgical wound and the bone regeneration. The same was developed with the aim of replacing the

Citation: Souza GMO, Borges CL, Ratis RNRS, Pedrosa VKL (2019) Use of Platelet-Rich Plasma in Autogenous Bone Graft in Implantology. Int J Oral Dent Health 5:096. doi.org/10.23937/24695734/1510096

Accepted: August 30, 2019: Published: September 02, 2019

Copyright: (c) 2019 Souza GMO, et al. This is an open-access article distributed under the terms of the Creative Commons Attribution License, which permits unrestricted use, distribution, and reproduction in any medium, provided the original author and source are credited. 
fibrin glue that put the patient at risk of cross infection, since it is a material that depends on the addition of bovine thrombin to be activated and the complexity of the production of its protocols, minimizing the complications resulting from this procedure used for over 60 years [8-10].

PRP is a gel with platelet concentration in a reduced volume of plasma. There are several methods of obtaining it, being able to be used in different scales and time of centrifugation. Generally the platelets are maintained in the plasma at a concentration of about 150,000 to $400,000 / \mathrm{mm}^{3}$; in PRP this concentration may increase about 2 or 3 times longer by autologous blood centrifugation [8].

Platelet-rich plasma is an organic, non-toxic, non-immunoreactive product collected in the preoperative period, rich in growth factors and derived from laboratory autogenous blood processing. Plasma gel is a compound derived from the mixture of thrombin and calcium gluconate to PRP. These products, when in the presence of calcium, trigger the organized formation of the clot through the transformation of fibrinogen into fibrin and activation of factor XII, resulting in the gelation of PRP, facilitating its application in surgical management of the grafts [11].

The preparation of the PRP requires aseptic conditions of manipulation of the blood, so as to avoid its contamination, and attention to the materials that are used, requiring a good blood bank infrastructure and a qualified professional [12].

The use of different protocols to obtain PRP is an unfavorable point, since it can induce different biological responses, and should be done with caution and taking into account several factors, such as the number, speed and time of centrifugations used, the number of platelets, the amount of growth factors and concentration of leukocytes and erythrocytes in a manner that provides a satisfactory biological effect and is successful in the preparation [13].

In addition, more research on the effectiveness of PRP should be performed, including the creation of a specific protocol, and patient preparation (use of some medications may interfere with platelet function by altering the properties of the gel), because its benefits have not been fully clarified [14].

\section{Preparation of PRP}

Despite presenting several protocols they follow a general sequence that will first go through the step of collecting the patient's blood $[15,16]$.

Blood collection should preferably be done using plastic syringes and plastic or siliconized tubes to prevent platelet activation and is performed with a needle size equal to or greater than $17 \mathrm{G}(1.3 \mathrm{~mm})$ in the median cubital vein to avoid trauma during collection of blood.
Usually are collected between 10 to $60 \mathrm{ml}$, adjusting the amount to the extent and type of surgery that will be performed. Subsequently the blood is placed in tubes containing anticoagulant (3.2\% sodium citrate) $[14,16$ 18].

The blood should then be centrifuged at $1200 \mathrm{rpm}$ for 10 minutes, capable of separating the platelets from the erythrocytes and promoting platelet salvage without any type of damage or lysis that may activate the anticipated secretion of growth factors [16].

Presenting two single and double centrifugation methods, Mazzocca, studied the differences between various systems for obtaining and administering PRP observed that all preparations of PRP resulted in a significant increase of platelets as compared to the normal concentrations present in the current blood. However, comparing the different concentrations obtained with the single centrifugation method and with the double centrifugation method, the author concluded that the double centrifugation method did not reveal significantly higher results in the level of platelet separation compared to the single centrifugation method. These findings support the efficacy of the single centrifugation method in the production of platelet count. In this soft-spin technique, blood is divided into three layers: The first layer consists of some platelets and acellular plasma, also called poor platelet plasma (PPP) or plasma that is poor in growth factors. In the intermediate zone, $n^{\circ} 1$ and $n^{\circ} 2$, we found a thin and whitish layer known as a "mist zone", consisting mainly of platelets

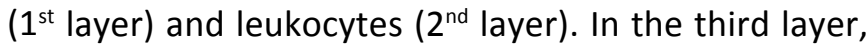
there are the erythrocytes which, due to their weight, are deposited in the lower part of the tube [19].

The first and second layers, just above the red cell layer, occupy the most important segment and must be aspirated together with a pipette, constituting the PRP, which must be deposited in a second tube and added with $10 \mu \mathrm{l}$ of a solution of calcium chloride to induce coagulation. Once coagulated, the PRP will be ready to fill from the injury site. The entire preparation procedure of PRP should be performed under strictly sterile conditions [20,21].

Relevant aspects for the preparation and characterization of PRP are acceleration and time of centrifugation, particle spacing, amount of blood volume processed, prevention of platelet aggregation and reduction of plasma volume (in the case of double centrifugation). The observation of these aspects ensures the quality of the PRP, allowing the variability of the results to be restricted to the autologous nature of the product $[16,22]$.

Activation of PRP may be through calcium replacement and initiation of the blood coagulation cascade, use of bovine thrombin although this may lead to coagulopathies and by the more preferable method that 
utilizes the centrifugal force applied to the separation of PRP, causing the membranes of the platelets are damaged by the high speeds of the centrifugation causing their premature activation. The incubation process for 1 hour at $37^{\circ} \mathrm{C}$ can also be taken as an alternative method of PRP activation $[17,23,24]$.

Around $70 \%$ of the growth factors are released in 10 minutes and $100 \%$ of the growth factors are released in 1 hour. The evaluation of the biological activity of platelet-derived growth factors is complex, so there is no way to evaluate the quality of the gel produced beforehand $[25,26]$.

\section{The Use of PRP in Implantodontia}

PRP can be used during implant placement as a surface treatment to stimulate osseointegration, in maxillary sinus lift, treatment of peri-implant bone defects (after peri-implantitis during placement of an implant with insufficient bone volume) or placement of implants after extraction [27]. Determining a good relation between hard and soft tissues, potentiating its regeneration in implant placement with the balance of fibrin formation and platelet activation, being responsible for the process and performance of the PRP gel [27-29].

\section{Methodology}

A literature review was performed on the efficacy of PRP in autogenous bone grafts in implantology. The databases used were PubMed, Scielo and BVS. In this study 30 papers from the years 1983 to 2017 were selected demonstrating the effectiveness of the technique.

\section{Discussion}

In the first attempts at PRP production, large autotransfusion equipment was used, but it was necessary to collect bulky blood samples and had a very high cost. Because there is no standard method of obtaining PRP, several protocols have been created in order to obtain better results in relation to the quality of the plasma with a good amount of platelets, through procedures in environments with little technology and that generate a lower cost [6]. As a result, the procedures were more susceptible to errors during preparation, interfering with the quality of the product.

Regardless of the protocol, it is necessary that it is able to increase the platelet count to a concentration well above that found in whole blood, as long as the structure and function of the platelets are preserved, otherwise the platelets may rupture and release the growth, interfering in the therapeutic action of PRP [30]. The blood volume required depends on the protocol used.

Marx [17], created a method that is now used as the basis for the creation of other protocols. The centrifugation was done in two steps, where 400 to $450 \mathrm{ml}$ (obtained by means of an Electro Medics 500 Medtronics gradient density cell separator) was collected from blood and subjected to a centrifugation of $5600 \mathrm{rpm}$ on the first centrifugation and 2400 on the second, where an approximate platelet enrichment of $338 \%$ was obtained, compared to the pre- PRP count in whole blood. F Vendramin, et al. [19] in its study, reached $496 \%$, with a 4.96-fold increase in platelet count in whole blood, applying a force of $300 \mathrm{~g}$ in the first centrifugation and 640 $\mathrm{g}$ in the second, with bench centrifuge. This indicates that you can get a satisfactory amount of platelets using simpler equipment with a smaller amount of blood, and in the Vendramin study you can suggest that the higher the strength in the second centrifugation, the higher the platelet concentration.

Marx [17] states that a dual-centrifugation protocol is essential so that one can truly concentrate the platelets during the preparation of PRP and that the single-centrifugation protocols do not produce PRP but rather a mixture of PPP and PRP. On the other hand, Anitua [28] recommends a single centrifugation protocol. Although the platelet concentration obtained with this procedure has not been demonstrated. Messora $\mathrm{M}$, et al. made an adaptation of the protocol of Anitua [28] to evaluate the single centrifugation, where he collected $10 \mathrm{ml}$ of blood volume, distributed and stored in vacuum tubes sodium citrate as anticoagulant. From each tube, 0.5 $\mathrm{mL}$ of blood was removed for platelet count, where it was then centrifuged at $160 \mathrm{~g}$ for 6 minutes, $1 \mathrm{~mL}$ of lean plasma from each tube was discarded, followed by collection of PRP, including 1 to $2 \mathrm{~mm}$ from the upper portion of the red blood cells, totaling a volume of approximately $1.2 \mathrm{ml}$ per tube. It was found that the low volume of PPP obtained in the centrifuged samples of them did not allow the preparation of PRP therapeutics according to the protocol of single centrifugation. Although blood centrifugation did not provide adequate platelet traction in the PRP samples, the platelet morphology was not affected, suggesting no platelet activation. This favorable aspect reflects an advantage of the single centrifugation protocol used in this study.

\section{Conclusion}

Research has demonstrated the effective use of PRP in the regeneration and tissue healing process, although further research with numbers and controls is needed to prove the quantitative and qualitative effectiveness of PRP, since there are few clinical studies in the literature. Uniformity is also required in the protocols adopted so that there is no discrepancy in the results obtained.

\section{References}

1. Tozum TF, Demiralp B (2003) Platelet-rich plasma: A promising innovation in dentistry. J Can Dent Assoc 69: 664.

2. Freymiller EA, Aghaloo TL (2004) Platelet-rich plasma: Ready or not? J Oral maxillofac Surg 62: 484-488. 
3. Sclafani AP, Romo T, Ukrainsky G, McCormick SA, Litner J, et al. (2005) Modulation of wound response and soft tissue ingrowth in synthetic and allogeneic implants with platelet concentrate. Arch Facial Plast Surg 7: 163-169.

4. Adler SC, Kent KJ (2002) Enhancing wound healing with growth factors. Facial Plast Surg Clin North Am 10: 129146.

5. Gandhi A, Doumas C, O'Connor JP, Parsons JR, Lin SS (2006) The effects of local platelet rich plasma on diabetic fracture healing. Bone 38: 540-546.

6. Caroline Peres Klein, Sandrine Comparsi Wagner, Jefferson Braga da Silva (2011) Obtenção de plasma rico em plaquetas: Avaliação do efeito da centrifugação sobre a concentração de plaquetas através da comparação entre protocolos. Revista Brasileira de Biociência 9: 509-513.

7. Bruno Avelar Santos (2009) Plasma rico em plaquetas: Verdades e controvérsias. UFMG.

8. Ribeiro DAST, Silva CO, Marson FC, Gama RJR, Neto Filho MDA (2015) Utilização do plasma rico em plaquetas (prp) na recuperação de tecidos ósseos. Braz J Surg Clin Res 11: 48-52.

9. Camargo GACG, Oliveira RLB, Fortes TMV, Santos TS (2012) Utilização do plasma rico em plaquetas na odontologia. Odontol Clín Cient 11: 187-190.

10. Dohan DM, Choukroun J, Diss A, Dohan SL, Dohan AJ, et al. (2006) Platelet rich fibrin (prf): A second-generation platelet concentrate. Part I: Technological concepts and evolution. Oral Surg Oral Med Oral Pathol Oral Radiol Endod 101: 37-44.

11. Pontual MAB, Margine RS (2004) Plasma rico em plaquetas (prp) e fatores de crescimento; das pesquisas científicas à clínica Odontológica. Livraria Santos Editora.

12. Camargo PM, Lekovic V, Weinlaender M, Vasilic N, Madzarevic M, et al. (2002) Platelet-rich plasma and bovine porous bone mineral combined with guided tissue regeneration in the treatment of intrabony defects in humans. J Period Res 37: 300-306.

13. Rego LAFL (2014) Plasma rico em plaquetas na implantologia. Universidade Fernando Pessoa, Porto.

14. Wilson EMK, Barbieri CH, Mazzer N (2006) Estimulação da cicatrização óssea pelo plasma autógeno rico em plaquetas. Estudo experimental em coelhos. Acta Ortop Bras 14.

15. Pacifi L, Casella F, Maggiore C (2002) Platelet rich plasma (prp): Potencialities and techniques of extration. Minerva Stomatol 51: 341-350.

16. Amanda GMP, José Fábio SDL, Ana Amélia Rodrigues, Angela Cristina ML, William DB, et al. (2014) Relevant aspects of centrifugation step in the preparation of plateletrich plasma. ISRN Hematology 2014: 1-8.

17. Marx RE (2001) Platelet-rich plasma (prp): What is prp and what is not prp? Implant dent 10: 225-228.
18. Civinini R, Macera A, Nistri L, Redl B, Innocenti M (2011) The use of autologous blood-derived growth factors in bone regeneration. Clin Cases Miner Bone Metab 8: 25-31.

19. Fabiel Spani Vendramin, Diogo Franco, Carmen Martins Nogueira, Mariana Sá Pereira, Talita Romero Franco (2006) Plasma rico em plaquetas e fatores de crescimento: Técnica de preparo e utilização em cirurgia plástica. R col Bras Cir 33: 24-28.

20. Antoniades HN, Williams LT (1983) Human platelet-derived growth factor: Structure and function. Fed Proc 42: 26302634.

21. Liu Y, Kalén A, Risto O, Wahlström O (2002) Fibroblast proliferation due to exposure to a platelet concentrate in vitro is pH dependent. Wound Repair Regen 10: 336-340.

22. Michel RM, Maria José HN, Flávia Aparecida CF, Tatiana MD, Luiz Gustavo NM, et al. (2010) Análise da eficiência do protocolo de dupla centrifugação para o preparo do plasma rico em plaquetas (PRP)-estudo experimental em coelhos. RSBO 6: 291-296.

23. Jeong Woo Lee, O Hyun Kwon, Taek Kyun Kim, Young Kyoo Cho, Kang Young Choi, et al. (2013) Platelet-rich plasma: Quantitative assessment of growth factor levels and comparative analysis of activated and inactivated groups. Arch Plast Surg 40: 530-535.

24. Marqui AC, Miguel DF, Magalhães JCA (2017) Comparação entre a técnica plasma rico em plaquetas e plasma rico em fibrina e sua utilização em odontologia. Revista Científica Multidisciplinar Núcleo do Conhecimento 13: 268-276.

25. Zechner W, Tangls S, Tepper G, Furst G, Bernhart T, et al. (2003) Influence of platelet-rich plasma on osseous healing of dental implants: A histologic and histomorphometric study in minipigs. Int J Oral Maxillofacial Implants 1: 15-22.

26. Reddi AH (1998) Role of morphogenetic proteins in skeletal tissue engineering and regeneration. Nat Biotechnol 16: 247-252.

27. Simonpieri A, Del Corso M, Vervelle A, Jimbo R, Inchingolo $F$, et al. (2012) Current knowledge and perspectives for the use of platelet rich plasma (prp) and platelet-rich fibrin (prf) in oral and maxillofacial surgery part 2: Bone graft, implant and reconstructive surgery. Curr Pharm Biotechnol 13: 1231-1256.

28. Tejero R, Anitua E, Orive G (1447) Toward the biomimetic implant surface: Biopolymers on titanium-based implants for bone regeneration. Progress in Polimeral Science 39: 1406-1447.

29. Lynch SE, de Castilla GR, Williams RC, Kiritsy CP, Howell $\mathrm{TH}$, et al. (1991) The effects of short-term application of a combination of platelet-derived and Insulin-like growth factors on periodontal wound healing. J Periodontol 62: 458467.

30. Lopez JL (2007) Plasma rico en factores de crecimiento y regeneración ósea. Revista Dentum, Barcelona 7: 108112. 